\title{
Job Stress study of Female Nurses working for Private and Public Hospitals from Urban Area.
}

\author{
Krupa A. Vyas \\ Department of Psyhology Smt.J.P.Shroff Arts College, Valsad
}

\begin{abstract}
It is an important task of working women to handle two important tasks. These most important tasks involve, justifying the responsibilities at work place and handling the responsibilities at home front. Balancing these two roles at home and work is very challenging task and causes stress at different levels. Different dimension of working women's life involves in evolving the stress in working women's life. These stresses cause the imbalance at the front of and handling family responsibility. The study is focusing on the stress causes among female nurses working for private and public hospitals from urban area. A sample of 70 female nurses from urban area participated in this study. Out of this, 35 each are from private and public hospitals respectively. A non-experimental, cross-sectional survey design was conducted using Demographic information form. The inventory used is based on 5 point scale. Using correlation and regression analysis, the result shows that there was significant difference in stress level between female nurses working in public and private hospitals. The measurement of stress level of occupational stress among working female nurses indicates the impact and occurrence of justification of job duties. The result can be applied for further research on working married women, especially concerning the impact and occurrence of job stress on patient's service and health. These results can be further applied to the studies concerning to mental health among the working women.

Key words: Occupational stress, working women, female nurses' occupational stress, correlation and regression, mental stress.
\end{abstract}

\section{Introduction}

Stress is very significant factor in human behaviour which affects the performance and health of individual. The environment of work place plays major role in generating the stress. Stress is a person's response to a stressor such as an environmental condition or a stimulus. Stress is a body's method of reacting to a challenge. According to the stressful event, the body's way to respond to stress is by sympathetic nervous system activation and it results in the response either in positive or negative manner. The current world is full of competition. The working female has to handle several fronts apart from obeying the duty at work place. There are many factors which causes the stress. Various stress generating factors can be list out as the working environment, responsibilities at work place, nature and response of superiors, performance evaluation and justification needs, interpersonal relationship with colleagues, family problems and responsibilities of family, insecurity pertaining to the work, monetary needs and economical personal conditions are some major factors which causes the stress.

Female working employees in private and public hospitals have different work culture and work environment. It is considered that the public sector have better financial security and considered as stable job. In compare to this, the private sector jobs are more demanding as far as performance is concern. The working environment and factors like job security, salary, leaves and responsibilities, job protection and several other factors are at different intensity for private and public sector working female nurses. This study aims to examine job stress of female nurses working for private and public hospitals.

Internationally, a considerable amount of study has occurred on the job stress, job satisfaction and occupational stress among female nurses. Nurse's job stress can have impact on both economic and personal implications. The stress leads to stress-related employee absenteeism, burnout and a negative impact on pupil outcomes (Kyriacou, 1987). According to Sodoma and Else (2009) a sharp increase in responsibilities in recent years has made the job more stressful. . Research on these topics is especially relevant in a context where teacher workloads are changing as a result of a number of factors, including the mainstreaming of pupils with special educational needs, greater ethnic diversity in classrooms and the increase in class sizes resulting from recent expenditure cuts (Merike Darmody and Emer Smyth, 2010).

Asad and Khan(2003) states that job stress is the effect of tension on an employee by the job pressures to fulfil job assignment and to respond to deadlines. Salik and Kamal(2007) mentioned that most people spend a considerable amount of their lives at work. D'souza, et al.,(2005) argued that the specific stress experienced by 
On Job Stress: A study of female nurses working for private and public hospitals from Urban Area.

people often depends on the nature and demands of the setting in which people live. Smith and Bourke (2002) explored work-related stress and job satisfaction among female and identified four aspects of stress: staff tensions and conflict, time pressure, students and classroom conditions, and lack of rewards and recognition. The job context, workload and satisfaction were found to affect stress directly.

\section{OBJECTIVES}

The main Objectives of this study are:

a. To identify the stress scenario among the private and public hospital female nurses.

b. To analyze the level of stress among the private and public hospital female nurses.

\section{HYPOTHESIS}

H0 (Null Hypothesis) : There is no significance difference between of stress level among the female nurses working at public and private hospitals of urban area.

Ha (Alternative Hypothesis): There is significance difference between the stress level among the female nurses working in private and public hospitals of urban area.

\section{Methods And Methodology}

This research work covers the female nurses of private and public hospitals from urban area of Valsad district. For the purpose of this study, using random sampling method, total sample size of 70 is covered where 35 samples represents female nurses from private hospitals and 35 represents female nurses from public hospitals. The primary data collected using Questionnaires for occupational stress by Shrivastav A.K. and Singh A.P.. The data collection is using random sampling method obtained from the urban area female nurses working at private or public hospitals. Against 90 questionnaires distributed, 39 questionnaires from female nurses working in public hospitals and 41 questionnaires from female nurses working in private hospitals were received. Ten questionnaires were rejected as they were incomplete and having lack of information. The response receive is $88.88 \%$. The education level of the 35 samples of public and private hospital nurses, 17 are undergraduate and 18 are graduate or above.

Table 1.1 Demography of collected Data

\section{Data Analysis}

\begin{tabular}{|c|c|c|c|}
\hline & Private Hospital Nurses & Public Hospital Nurses & Total \\
\hline Under Graduate Nurses & 17 & 17 & 34 \\
\hline Graduate Nurses & 18 & 18 & 36 \\
\hline Total: & 35 & 35 & 70 \\
\hline
\end{tabular}

Table 1.2

Decision Range based on score

\begin{tabular}{ll}
\hline Range & Decision Criteria \\
\hline$<=\mathbf{5 0}$ & No Stress \\
\hline$>\mathbf{5 0}$ and $<=\mathbf{1 0 0}$ & Low Stress \\
\hline$>\mathbf{1 0 0}$ and $<=\mathbf{1 5 0}$ & High Stress \\
\hline$>\mathbf{1 5 0}$ & Very High Stress \\
\hline
\end{tabular}

Table 1.3 Mean value for Private Hospital Nurses(n=35) and Public Hospital Nurses (n=35)

\begin{tabular}{|c|c|c|c|}
\hline & Private Hospital $\left(\mathbf{M}_{\mathbf{x} 1}\right)$ & Public Hospital $\left(\mathbf{M}_{\mathbf{x} 2}\right)$ & $\mathbf{M}_{\mathbf{x}}$ \\
\hline Under Graduate & $\mathbf{1 1 8 . 4 4}$ & $\mathbf{9 8 . 3 5}$ & $\mathbf{1 0 8 . 4 0}$ \\
\hline Graduate & $\mathbf{1 2 9 . 8 9}$ & $\mathbf{1 0 3 . 7 1}$ & 116.8 \\
\hline $\mathbf{M}_{\mathbf{x}}$ & $\mathbf{1 2 4 . 1 7}$ & $\mathbf{1 0 1 . 0 3}$ & \\
\hline
\end{tabular}




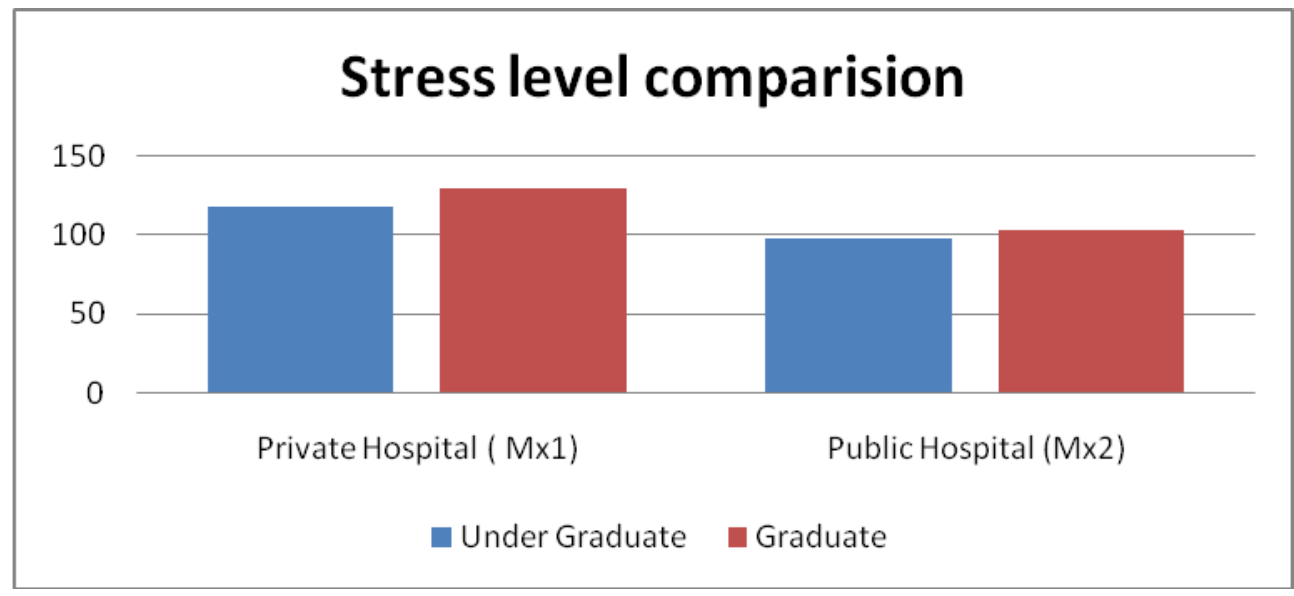

Table 1.4 t-test

\begin{tabular}{|c|c|c|c|}
\hline & Public Hospital Nurses & Private Hospital Nurses & \\
\hline$N$ & 35 & 35 & Sample Size \\
\hline$\sum x$ & 3435 & 4470 & \\
\hline $\mathrm{M}_{\mathrm{x}}$ & 140.5769 & 140.0769 & Mean Value \\
\hline$\sum \mathrm{x}^{2}$ & 521131 & 516220 & \\
\hline$\left(\sum \mathrm{x}\right)^{2}$ & 13359025 & 13264164 & \\
\hline$\left(\sum x\right)^{2} / n$ & 513808.7 & 510160.2 & \\
\hline$\sum \mathrm{d}^{2}$ & 7322.346 & 6059.846 & \\
\hline$\sigma^{2}$ & 292.8938 & 242.3938 & \\
\hline $\mathrm{S}_{\mathrm{d}}{ }^{2}$ & & & 20.58799 \\
\hline $\mathrm{S}_{\mathrm{d}}$ & & & 4.537399 \\
\hline $\begin{array}{c}t \text {-value } \\
\text { (Calculated) }\end{array}$ & & & 1.0015 \\
\hline $\begin{array}{c}t \text {-value } \\
\text { (Critical) } \\
\alpha=0.05\end{array}$ & & & 1.671 \\
\hline
\end{tabular}

$\mathbf{t}(68)=1.671, p<0.05$

\section{Conclusion}

Here, the sample size is 35 each for private and public sector nurses. Thus the sample size is higher than 30 and large. The degree of freedom $\mathrm{df}=68$. We will use z-test in this case. For the calculated absolute value of $\mathrm{t}=1.0015$ for $\mathrm{df}($ degree of freedom $)=68$ and $\alpha=0.05$, the corresponding critical value of $\mathrm{t}$ obtained is 1.671. Since, $t_{\text {caclculated }}<t_{\text {critical }}$, we fail to reject $H_{0}$ and thus conclude that there is no significant stress level difference between urban area female nurses working for private hospitals and urban area female nurses working for public hospitals.

No significant difference was found between female nurses of private hospitals from urban area and female hospital nurses of public sector from urban area in terms of their work stress, $t(68)=1.671, p=.05$. On a five-point scale work stress test, female nurses of public hospitals of urban area averaged 140.5769 and private hospital female nurses of urban area averaged 140.0769.

\section{References}

[1] Derith Dana - Lee(2001) "The effect of social support and self Esteem on the Development of Depressive Symptomatology in women with non traditional professional careers", Dissertation Abstracts - International Section-B, The Science and Engeering, February, 61(7B),pp.38-39

[2] Handwerker W. Penn.(1999) "Cutural Diversity, stress and Depression; working women in the Americas", Journal of Women's Health and Gender Based Medicine, Pub:US:Mary ann Liebert Inc., Dec, 8(10), pp.1303-1311.

[3] Molina, Olga(2000) "Stresses and strengths of working women in a divorce support group", Journal of Divorce and remarriage, 33(3-4), pp.145-148.

[4] Powers, Sharon. Elizabeth(2000) "Married employed mothers and role conflicts", Dissertation - Abstracts. International - section B. The Science and Engineering, 60(12B), pp.63-79.

[5] Sevim, S.A., 2006. Religious tendency and gender roles: Predictors of the attitudes toward women's work roles. Soc. Behav. Personal. Intl. J., 34: 77-86. DOI: 10.2224/sbp.2006.34.1.77

[6] Sharma , Raltan Yadav, Asha Yadav, Amrita(2001) "Mental Health of women in relation to job stress", Journal of Personality and clinical studies, Pub. India Journal of Personality and Clinical Studies, 17(1), pp.41-44.

[7] Goode, W.J., 1964. Readings on the Family and Society. 1st Edn., Prentice-Hall, Englewood Cliffs, N.J., pp: 242.

[8] Lu, Y.Y., 2007. The impact of work-family conflict on working women in Taiwan: The effects of organizational support. Ph.D. Thesis. Queensland University of Technology, Brisbane, Australia.

[9] Mosby, Inc., 2009. Mosby’s Medical Dictionary. $8^{\text {th }}$ Edn., Mosby/Elsevier, New York, USA., ISBN-10:0323052908, pp: 1998 